\title{
Dental Students' Preparation and Study Habits for the National Board Dental Examination Part I
}

\author{
Nathan Hawley, B.A.; Devin Johnson, D.M.D.; Keith Packer, D.M.D.; \\ Marcia Ditmyer, Ph.D.; Karl Kingsley, Ph.D.
}

Abstract: The purpose of this study was to assess dental students' study habits and level of preparation necessary to successfully prepare for the National Board Dental Examination (NBDE) Part I. Four hundred thirty-seven dental students from across the United States participated in a web-based survey about their goals, results, and study habits in preparation for taking the NBDE Part I. A majority of the respondents ( 76 percent; $n=331$ ) reported taking the web-based version of the exam. More than one-third $(n=168)$ of the respondents indicated they wanted to achieve a scaled score of 90 or above, while only about one-quarter ( $n=120)$ actually achieved this target score. Students preferred to use the Dental Decks and released Part I exams to study for the exam, regardless of their score. No significant correlations between type of study source used and the score achieved on the exam were found.

Mr. Hawley is a third-year dental student at the University of Nevada, Las Vegas, School of Dental Medicine; Dr. Johnson is an orthodontic resident at the University of Michigan School of Dentistry; Dr. Packer is an orthodontic resident at the University of Colorado Denver School of Dental Medicine; Dr. Ditmyer is Assistant Professor in Residence, Department of Professional Studies, University of Nevada, Las Vegas, School of Dental Medicine; and Dr. Kingsley is Assistant Professor, Department of Biomedical Sciences, University of Nevada, Las Vegas, School of Dental Medicine. Direct correspondence and requests for reprints to Dr. Marcia Ditmyer, School of Dental Medicine, University of Nevada, Las Vegas, 1001 Shadow Lane, MS 7410, Las Vegas, NV 89031; 702-774-2646 phone; 800-549-8707 fax; marcia.ditmyer@unlv.edu.

Keywords: National Board Dental Examination, test preparation, dental student study habits

Submitted for publication 4/6/09; accepted 7/20/09

$\mathrm{T}$ The National Board Dental Examination (NBDE) is developed and administered by the Joint Commission on National Dental Examinations (JCNDE). The purpose of the NBDE Parts I and II is to assist state boards in determining qualifications of dentists seeking licensure to practice dentistry. The examination assesses candidates' ability to understand information from the basic biomedical and dental sciences, as well as application of this information in problem-solving contexts. All fifty-three U.S. licensing jurisdictions recognize the NBDE results.

The NBDE Part I consists of 400 multiplechoice questions distributed across four discipline areas: 1) anatomic sciences, 2) biochemistry-physiology, 3) microbiology-pathology, and 4) dental anatomy-occlusion. Items from these four areas are randomly distributed throughout the examination. The 400 multiple-choice items are divided into two 3.5-hour sessions that include 200 items each. ${ }^{1,2}$ The examination currently consists of 80 percent independent discipline-based items and 20 percent testlet-based items, which are problem- or scenariobased. In 2007, the format of Part I was changed from the traditional paper and pencil format offered twice yearly to a web-based examination that can be taken at any time, provided the student meets the testing requirements.

A candidate's total overall score is reported in standard scores (ranging from 49 to 99) converted from the raw scores with a minimum passing score equal to, or greater than, $75 .^{1,2}$ The raw score needed to achieve the passing standard score is set by a group of experts using appropriate psychometric techniques. The scores reported do not represent the number correct or the percentage correct by any one candidate. The purpose of the conversion from raw scores to standard scores allows for comparison of results from different versions of the exam along one single measurement scale. Although criteria for passing are based on the standard scores, raw scores are still provided for each individual section. In March 2008, the JCNDE voted to change the scoring to a pass/fail system, which is scheduled to begin in 2012. ${ }^{3}$ Raw scores will still be provided for each knowledge area, but there will be no cut-off standard score reported; only an indication of pass or fail will be officially reported. 
Most students complete the NBDE Part I after their second year of dental school. Even though the JCNDE has said that the exam is not a valid instrument to be used in comparing applicants to postgraduate dental education and specialty programs, the exam has traditionally been used in this capacity. ${ }^{4}$ Therefore, students interested in pursuing advanced education and specialty programs have viewed scoring highly on the exam as an essential component of their applications. ${ }^{5}$

Students' approaches to studying for the NBDE Part I are varied. Previous research has suggested that formal board review sessions may not be the most effective form of preparation, but that students rated using Dental Decks and released Part I exams as the most helpful study materials. ${ }^{6}$ While informative, these findings were based on a study with a limited sample pool of only sixty-four students, all from the same dental school.

The purpose of our study was to build upon the previous research and more thoroughly examine students' perceptions of the most effective study habits and level of preparation needed to successfully prepare for the NBDE Part I. Additionally, this study explored whether students who are seeking to score highly on the NBDE Part I (defined as a 90+ standard score) used different materials or different time frames than students who are not.

\section{Methods}

This study was conducted using a web-based survey instrument from Zoomerang (San Francisco, CA). An explanation and request for informed consent, along with the link to the survey, were distributed via email to student representatives from all U.S. dental schools. The student representatives who received the email were asked to forward and distribute the survey to students at their school who had completed the NBDE Part I. Participation was voluntary, and all information remains confidential since there is no link between survey responses and the individual students who participated. Only students at an accredited U.S. dental school were solicited for participation in this study. This study was approved by the University of Nevada, Las Vegas, Institutional Review Board (IRB Protocol \# 0609-2079).

The survey consisted of thirty-seven questions, comprised of both multiple-choice and free response answers. Some rudimentary demographic questions were included in the instrument, although the survey did not require participants to indicate where they attended dental school or ask for other demographic information that could be used to potentially identify them. The instrument was reviewed by three experts for face validity. Cronbach's alpha was used to assess internal reliability $(\mathrm{r}=0.87)$, and test-retest was conducted to assess stability-reliability $(\mathrm{r}=0.076)$. Data were analyzed using S-PLUS version 8.0, using descriptive statistics and chi-square analysis.

\section{Results}

A total of 437 U.S. dental students participated in this study. Slightly more than half $(\mathrm{n}=232,53.09$ percent) reported attending a public dental school, were male ( $n=234,53.55$ percent), and reported their age as being twenty-five to thirty $(\mathrm{n}=259,59.27$ percent). Additionally, the vast majority ( $\mathrm{n}=387,88.56$ percent) reported taking the NBDE Part I during their second year, while the remaining students reported taking it during their first year. Approximately threefourths of the respondents ( $n=331,75.74$ percent) had taken the web-based version of the exam.

Of the students in the study, more than one-third ( $n=168,38.44$ percent) indicated their goal for the NBDE Part I was to achieve a standard score of 90 or above. About one-quarter ( $\mathrm{n}=120,27.46$ percent) indicated they were trying to score above an 80 , while the remainder either wanted to score above the national average ( $n=52,11.9$ percent) or were just trying to pass ( $\mathrm{n}=96,21.97$ percent). The breakdown of student self-reported scores was approximately one-fourth scoring above a 90 ( $n=106,24.26$ percent), about one-third scoring 85 to $89(\mathrm{n}=150,34.32$ percent) or 80 to 84 ( $\mathrm{n}=126,28.83$ percent), and about 10 percent scoring 75 to $79(\mathrm{n}=44,10.07$ percent $)$ and 74 or below ( $n=4,0.92$ percent).

Overall, the majority of students identified the dental anatomy section ( $\mathrm{n}=266,60.87$ percent) as the section for which they felt the most prepared, while 42.56 percent $(n=186)$ identified the biochemistry/ physiology section as the section for which they felt least prepared. On the actual test, 56.52 percent $(n=247)$ scored highest on the dental anatomy section, while 33.41 percent $(n=146)$ scored lowest on the anatomical sciences and 30.66 percent $(n=134)$ scored lowest on the biochemistry/physiology section (Figure 1). There were significant correlations between the section for which the students felt most prepared and the section in which the students actu- 


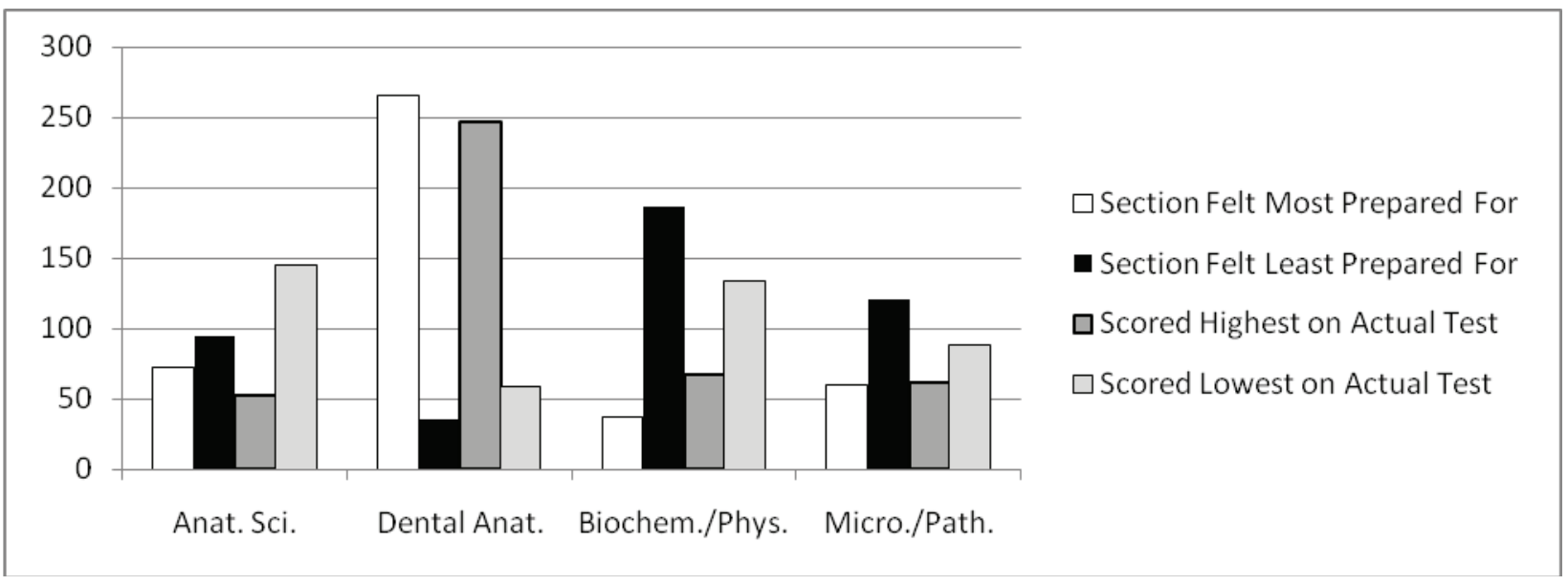

Figure 1. Dental students' indication of which sections they were most and least prepared for and sections of actual highest and lowest scores $(n=437)$

ally scored the highest $(\mathrm{r}=0.357 ; \mathrm{p}<0.01)$. Moreover, significant correlations were also found between the sections for which the students felt least prepared and the sections in which the students actually scored the lowest $(r=0.433 ; \mathrm{p}<.01)$.

Approximately two-thirds $(n=289,66.13$ percent) of the respondents reported using the Dental Decks as their primary study tool. However, there was no statistical correlation found between respondents' self-reported score and their choice of primary study tool. Students were also asked to identify the sources they used in preparing for the test, how helpful these sources were, and how much study time they devoted to that source. These composite results are summarized in Table 1.

Most students started studying for the NBDE Part I one to three months before the exam $(n=271$, 62.01 percent). A smaller percentage of students reported studying less than one month $(n=83,18.99$ percent), as well as four to six months before the exam ( $n=64,14.65$ percent). The greatest number of students ( $\mathrm{n}=157,35.93$ percent) reported studying between ten and twenty hours per week. Some students reported studying more than thirty hours per week ( $\mathrm{n}=98,22.43$ percent), twenty-one to thirty hours per week ( $\mathrm{n}=92,21.05$ percent), and less than ten hours per week ( $\mathrm{n}=66,15.1$ percent). No statistical correlation was found between the self-reported score and number of months a student studied for the exam. However, a very weak correlation $(\mathrm{r}=0.225$; $\mathrm{p}<.01$ ) between the number of hours studied per week and the student's self-reported score was found. Also, a very weak correlation $(\mathrm{r}=0.215 ; \mathrm{p}<.01)$ between the student's desired score and the number of hours studied per week was observed.

More than half of the respondents $(n=254$, 58.12 percent) reported that their university offered some form of board review course. In addition, 37.3 percent $(n=163)$ reported that their university gave them one to three weeks of dedicated curricular release time off to study, while 19.91 percent $(n=87)$ reported having no time off and 14.64 percent $(n=64)$ reported having four to five weeks off to study. There was a very weak correlation $(r=0.306 ; \mathrm{p}<.01)$ between the length of dedicated time the university allowed for student study time off and how many hours per week the students studied. Most students responded that their school did either a fair job $(n=186,42.56$ percent) or a very good job ( $\mathrm{n}=136,31.13$ percent) at preparing them. Finally, there was a very weak correlation $(r=0.203 ; p<.01)$ between how well the students perceived the university had prepared them and the student's self-reported score.

\section{Discussion}

The larger sample size (n) in this study and the inclusion of more U.S. dental schools than in the previous study allow for a greater ability to 


\begin{tabular}{|c|c|c|c|c|c|c|c|c|c|c|}
\hline \multirow[t]{2}{*}{ Source } & \multicolumn{2}{|c|}{ Source } & \multicolumn{4}{|c|}{ Helpfulness of Source } & \multicolumn{4}{|c|}{ Percent of Study Time Devoted to Source } \\
\hline & $\begin{array}{l}\text { Primary } \\
\text { Source }\end{array}$ & $\begin{array}{l}\text { Additional } \\
\text { Source }\end{array}$ & $\begin{array}{l}\text { Very } \\
\text { Helpful }\end{array}$ & $\begin{array}{c}\text { Somewhat } \\
\text { Helpful }\end{array}$ & $\begin{array}{c}\text { Not Very } \\
\text { Helpful }\end{array}$ & $\begin{array}{l}\text { Not at } \\
\text { All Helpful }\end{array}$ & $<5 \%$ & $5-10 \%$ & $11-15 \%$ & $>15 \%$ \\
\hline $\begin{array}{l}\text { Released } \\
\text { National } \\
\text { Boards Exam }\end{array}$ & $57(13 \%)$ & $297(68 \%)$ & $194(44 \%)$ & $184(42 \%)$ & $33(8 \%)$ & $8(2 \%)$ & $58(13 \%)$ & $112(26 \%)$ & $99(23 \%)$ & $167(38 \%)$ \\
\hline Dental Decks & $289(66 \%)$ & $128(29 \%)$ & $175(40 \%)$ & $200(46 \%)$ & $37(8 \%)$ & $8(2 \%)$ & $17(4 \%)$ & $26(6 \%)$ & $26(6 \%)$ & $357(82 \%)$ \\
\hline DentalStax & $12(3 \%)$ & $22(5 \%)$ & $5(1 \%)$ & $26(6 \%)$ & $9(2 \%)$ & $10(2 \%)$ & $243(56 \%)$ & $9(2 \%)$ & $10(2 \%)$ & $14(3 \%)$ \\
\hline Review Course & $13(3 \%)$ & $97(22 \%)$ & $22(5 \%)$ & $104(24 \%)$ & $42(10 \%)$ & $16(4 \%)$ & $206(47 \%)$ & $51(12 \%)$ & $36(8 \%)$ & 26 (6\%) \\
\hline Class Notes & $13(3 \%)$ & 143 (33\%) & $57(13 \%)$ & $162(37 \%)$ & $66(15 \%)$ & $8(2 \%)$ & $230(53 \%)$ & $73(17 \%)$ & 31 (7\%) & $42(10 \%)$ \\
\hline Textbooks & 12 (3\%) & 164 (38\%) & 81 (19\%) & $176(40 \%)$ & $33(8 \%)$ & $5(1 \%)$ & $202(46 \%)$ & $90(21 \%)$ & 39 (9\%) & $48(11 \%)$ \\
\hline Other & 38 (9\%) & & $57(13 \%)$ & 82 (19\%) & $6(1 \%)$ & $3(1 \%)$ & $178(41 \%)$ & $44(10 \%)$ & $18(4 \%)$ & $57(13 \%)$ \\
\hline
\end{tabular}

more thoroughly analyze the various inputs, such as demographic factors, that may influence student achievement on the NBDE Part I. For example, while educators have long debated whether the quality of instruction and resources in private versus public institutions influences NBDE outcomes (choice of institution), no correlation between NBDE score and the type of institution was observed in this study. This finding may have broader implications, demonstrating that these institutional differences may, in fact, be less consequential for student achievement on this particular evaluation than previously thought. Moreover, the results also suggest that student-directed study and effort may be the primary determinants of NBDE Part I success regardless of institutional choice. Secondly, dental education has focused in recent years on improving the enrollment percentage and retention of females in dental education, and the results of this study provide further evidence that gender may not be an important factor that influences scores.

While more than one-third of the students reported they were seeking to score at least a 90 on the exam, only about one-quarter actually scored at this level, providing quantification of many previous anecdotal reports describing this disparity. Interestingly, students reported the sections for which they felt the most and the least prepared, which accurately predicted the sections of their highest, as well as their lowest, scores. For example, students felt the most prepared for dental anatomy and scored the highest on this section. Conversely, students felt least prepared for biochemistry/physiology, which accurately predicted one of the two sections for which they received the lowest score. This information is critical for students as they prepare for this evaluation. Their individual perceptions about which section is their weakest may not only be valid and predictive, but if future students are to efficiently allocate their time and resources to improve their score, these data suggest reallocation from their strongest subject to their weakest may represent an alternative strategy that could have a greater overall impact on improving their NBDE score than focusing on their areas of perceived strength.

Although the students reported feeling the most prepared for dental anatomy, the design of this study does not allow for the further elucidation of why this may be true. One possibility is that this topic is fairly limited in nature, when compared with the broader content of the combined biochemistry/physiology section. Another possibility is that the retrospective nature of this study may have influenced whether the students felt they were more prepared for a particular section because they, in fact, were or because their final score in that section has influenced their perception of readiness over time. The limited scope of this study does not allow for further analysis of these questions, but suggests rather interesting topics for future investigations.

This study confirmed a previous study ${ }^{6}$ that found students preferred using Dental Decks and released Part I exams as their primary resources for studying for the NBDE Part I. However, the analysis of these data provided some new insights about their effectiveness. For instance, although students 
reported using these as their primary study tools, the actual choice of aid was not a significant predictor of final score. This finding suggests that although these tools are effective study aids, their use (or use of alternative aids) does not impact students' overall score. If variables such as gender, school, and choice of study tools do not impact overall NBDE scores, what factors are significant?

New evidence about such variables emerged from this study, which may be useful for both dental students and faculty. For instance, although the number of months dedicated to study was not predictive, the average number of reported hours per week studied was. Furthermore, the number of hours per week studied was linked with the amount of curricular release time allocated by the institution. These findings suggest that dental school educators and administrators may want to evaluate the benefits of, and consequently accommodate, dedicated curricular release time to facilitate student-directed study as an integral part of NBDE Part I preparation. As some dental schools had no specific time off for this purpose, a rescheduling or restructuring to allow dedicated study time may yield significant improvements in average student scores. Moreover, although the vast majority of students took the NBDE Part I in their second year, the differences between scores of students taken after the first or second year of dental school were not significant. These results, although preliminary, may suggest that some condensation and decompression of the current dental curriculum, now being discussed by the American Dental Association (ADA) and the American Dental Education Association (ADEA), may be possible in many schools without negatively impacting NBDE scores.

\section{Conclusion}

Most dental students in this study, regardless of desired score on the NBDE Part I, reported using the Dental Decks and released Part I exams as their primary study materials. Achieving a scaled score of 90 or above could not be predicted by the study sources a student used, the number of months a student studied, or the gender of the student. The only predictor of score was the number of hours a student studied each week. As students were able to predict their weakest section, this information could be used to assist students as they prepare for the NBDE Part I. Moreover, these data suggest dedicated curricular release time increased the number of hours per week a student studied and number of hours per week studied associated with higher scores, providing rationale to provide, or retain, dedicated curricular release time in the interest of student achievement and student outcomes. Given the disparity between those striving for 90 and above and the actual number of students who achieved this score, this information becomes even more important for planning and study preparation, as well as the directed allocation of time and discipline-specific resources.

\section{REFERENCES}

1. American Dental Association. National Board Dental Examination Part I 2008 candidate guide. At: www.ada. org/prof/ed/testing/nbde01/nbde01_guide.pdf. Accessed: October 17, 2008.

2. American Dental Association. National Board Dental Examination Part I frequently asked questions. At: www.ada. org/prof/ed/testing/nbde01/nbde01_faq.pdf. Accessed: October 17, 2008.

3. Joint Commission on National Dental Examinations. Unofficial report of major actions, April 8, 2009. At: www. ada.org/prof/ed/testing/act_jcnde.pdf. Accessed: July 1, 2009.

4. Joint Commission on National Dental Examinations. Fact sheet regarding commission policy changes reporting pass/fail on candidate performance beginning 2010. Chicago: Joint Commission on National Dental Examinations, 2008.

5. Neumann LM, MacNeil RL. Revisiting the National Board Dental Examination. J Dent Educ 2007;71(10):128192.

6. Wright EF, Henzi D. Preparation course for Part I of the national dental boards: lessons learned. J Dent Educ 2007;71(6):785-96. 